Check for updates

Cite this: Nanoscale Adv., 2019, 1, 213

\title{
Synthesis of $\gamma$-alumina $\left(\mathrm{Al}_{2} \mathrm{O}_{3}\right)$ nanoparticles and their potential for use as an adsorbent in the removal of methylene blue dye from industrial wastewater
}

\begin{abstract}
Shafqat Ali, (D) *a Yasir Abbas, ${ }^{b}$ Zareen Zuhra $^{\text {b }}{ }^{b}$ and lan S. Butler
Non-toxic nanomaterials have gained significant importance recently in the treatment of industrial wastewater that sometimes contains organic dyes such as methylene blue. We report here an easy approach for the synthesis of $\gamma$-alumina $\left(\mathrm{Al}_{2} \mathrm{O}_{3}\right)$ nanoparticles via a method that incorporates the use of formamide and the non-ionic surfactant Tween-80. Together, formamide and Tween-80 serve as an effective precipitating agent and a convenient synthetic template, respectively, in directing the growth of the alumina nanoparticles. The morphology and structure of the nanoparticles were investigated by FTIR, XRD, TGA, SEM, EDX, elemental mapping and TEM methods. The sizes of the nanoparticles are in the $30-50 \mathrm{~nm}$ range. The maximum pore size is $4.13 \mathrm{~nm}$ and the surface area is $112.9 \mathrm{~m}^{2} \mathrm{~g}^{-1}$ as determined by the Brunauer-Emmett-Teller (BET) method. The nanomaterials are excellent adsorbents for the cationic methylene blue dye from aqueous solution. The effects of $\mathrm{pH}$, time, temperature and concentration on the adsorption have been examined and the adsorption capacity increased from 490 to $2210 \mathrm{mg} \mathrm{g}^{-1}$ as the initial concentration was increased from 50 to $400 \mathrm{mg} \mathrm{L}^{-1}$ under the following conditions: $\mathrm{pH} 9,10 \mathrm{~min}$ reaction time, and $60{ }^{\circ} \mathrm{C}$. The adsorption mechanism is considered to encompass electrostatic interactions in water between the $\mathrm{Al}_{2} \mathrm{O}_{3}$ nanoparticles and the cationic methylene blue dye. These readily made nanoparticles may well prove useful in both wastewater treatment and industrial catalysis.
\end{abstract}

Received 7th June 2018

Accepted 29th August 2018

DOI: $10.1039 / c 8 n a 00014$

rsc.li/nanoscale-advances

\section{Introduction}

Organic dyes are cost-effective materials with many industrial uses, for example, in coatings, paper making, leather tanning, plastics, food, detergents, textiles and agriculture. ${ }^{1,2}$ Owing to their widespread use, however, they now pose a serious environmental problem throughout the world. ${ }^{3}$ The safe disposal of organic dyes is a crucial issue as they contaminate not only surface water but also underground water reservoirs. ${ }^{4,5}$ Prior treatment of industrial wastewaters is an important concern that must be addressed before they can be safely discharged from industrial sites. Several physical, chemical and biological methods have been developed recently for the destruction, removal and shipment of organic dyes prior to their release in wastewaters. ${ }^{6-10}$ These methods include adsorption, absorption, membrane separation, flocculation and coagulation, as well as electrochemical and catalysis approaches. ${ }^{11-13}$ Despite these

${ }^{a}$ The Key Laboratory of Advanced Materials of Ministry of Education, School of Material Science and Engineering, Tsinghua University, Beijing 100084, China. E-mail: shafqatali@mail.tsinghua.edu.cn; Fax: +86-10-64421693

${ }^{b}$ State Key Laboratory of Chemical Resource Engineering, Institute of Science, Beijing University of Chemical Technology, Beijing 100029, P. R. China

'Department of Chemistry, McGill University, Montreal, QC H3A 2K6, Canada developments, the complete removal of organic dyes from the environment is still a challenge owing to possible by-product formation. ${ }^{14-17}$ Consequently, the design of an easy, inexpensive and green method of removal of organic dyes from wastewater is an important research area.

Nano- and micro-sized materials present interesting possibilities for the complete removal of organic dyes, such as methylene blue (MB) dye from wastewaters. Because of their small size and high surface area, these materials have the ability to act as filtration media as well as catalysts. ${ }^{18-21}$ To date, many efforts have been focused on such materials in the form of particles, spheres, sheets, wires, rods, tubes and thorns since these different morphologies afford opportunities for many potential applications. ${ }^{18,22-24}$ Precipitation is an easy, simple and cost-effective method for the synthesis of nanoparticles and their composites, especially when the solvent used can be recycled. ${ }^{25}$ The surface properties of the materials being produced can be influenced by controlling the concentration, the solvent, and the calcination step depending on the needs of a given application. There are many nanomaterials now commercially available so that adsorbents can be tailored for a specific requirement. ${ }^{26-29}$ Moreover, the use of surfactants like cetyltrimethylammonium bromide (CTAB), tetrapropylammonium bromide (TPAB), polyethylene glycol 
(PEG), sodium dodecyl sulfate (SDS) and polyvinyl pyrrolidone can help in the formation of special morphologies. ${ }^{30-33}$ Another nonionic surfactant, polyoxyethylene sorbitan monooleate, commercially known as Tween-80, also plays an important role in directing the morphology and size formation of nanomaterials. ${ }^{34}$

We have recently described some new cross-linked hybrid materials, based on ferrocene and cyclotriphosphazene, that have excellent electrochemical and fluorescence properties. These materials have been shown to be excellent adsorbents for the removal of $\mathrm{MB}$, when used together with Tween-80 to produce CuO nanostructures. ${ }^{35,36}$ This dye is toxic if swallowed or when it comes into direct contact with skin. It can also cause damage to various human organs, e.g., eyes, and the central nervous system. ${ }^{37} \cdot \gamma$-Alumina $\left(\mathrm{Al}_{2} \mathrm{O}_{3}\right)$ materials have been the subject of significant research, but they have been less studied for the removal of toxic organic dyes. We report here the facile synthesis of these nanoparticles with the help of formamide and Tween-80. These nanoparticles may possibly exhibit quantum confinement effects. ${ }^{37}$ In addition, the possibility of using these particles for the adsorption of the hazardous MB dye from aqueous solutions was examined and the results are described here.

\section{Materials and reagents}

$\mathrm{AlCl}_{3} \cdot 6 \mathrm{H}_{2} \mathrm{O}, \mathrm{HCl}$ and $\mathrm{NaOH}$, liquid ammonia, methylene blue and highest purity ethanol (98\%) were obtained from Beijing Chemical Works.

\subsection{Characterization}

Fourier transform infrared spectra (30 co-added scans) were obtained using a Bruker Vertex 70 FT-IR spectrometer. The ultraviolet-visible (UV-Vis) absorbance spectra were recorded on a Lambda 950 UV-Vis spectrophotometer (Perkin-Elmer, Inc., USA). Thermogravimetric analyses (TGA) were conducted on a Netzsch STA 449C system with a heating rate of $20{ }^{\circ} \mathrm{C} \mathrm{min}{ }^{-1}$ in a nitrogen atmosphere. The surface morphologies of the products were examined on a JOEL JSM-6701F field emission scanning electron microscope (SEM) at an accelerating voltage of 20 $\mathrm{kV}$ after the samples had been coated with $\sim 5 \mathrm{~nm}$ of a palladium-gold alloy. Transmission electron microscopy (TEM) images were obtained on a JEOL JEM-100CX microscope from samples obtained by adding a few drops of ethanol into the sample tubes prior to ultra-sonication and then placing a drop of this mixture onto copper grids coated with carbon. The pore sizes of the samples were determined from the nitrogen adsorptiondesorption isotherms obtained at $77 \mathrm{~K}$ on a Micrometrics ASAP 2460 system using the Brunauer-Emmett-Teller (BET) method. X-ray powder diffraction analyses were performed on a D8 Advance Bruker system using $\mathrm{CuK}_{\alpha}\left(=0.15406 \mathrm{~nm}, 2 \theta=5-90^{\circ}\right)$ radiation. Finally, a Hitachi EDX elemental microanalysis and mapping system and a JEOL-3010 instrument were used to obtain the elemental compositions.

\subsection{Growth of $\gamma$-alumina nanoparticles}

The $\gamma$-alumina nanoparticles were synthesized via a precipitation method in water. $0.4 \mathrm{M} \mathrm{AlCl} 3 \cdot 6 \mathrm{H}_{2} \mathrm{O}$ was dissolved in
$120 \mathrm{~mL}$ of deionized water and $4 \mathrm{~mL}$ of Tween- 80 was added to this solution. After $1 \mathrm{~h}$, a $50 \%$ aqueous solution of formamide, as the precipitation agent, was added dropwise to the mixture with continuous ultrasonication $(150 \mathrm{~W}$ and $40 \mathrm{kHz})$ at $60^{\circ} \mathrm{C}$ for $3 \mathrm{~h}$. A gelatinous white precipitate was produced indicating the formation of $\mathrm{Al}(\mathrm{OH})_{3}$. This precipitate was filtered off and washed with ethanol and water several times. After drying, the resulting white gel was calcined in a muffle furnace at $550{ }^{\circ} \mathrm{C}$ for $5 \mathrm{~h}$ in the presence of air at a heating rate of $5{ }^{\circ} \mathrm{C} \min ^{-1}$, thus transforming the $\mathrm{Al}(\mathrm{OH})_{3}$ into $\mathrm{Al}_{2} \mathrm{O}_{3}$ nanoparticles.

\subsection{Adsorption experiments}

The adsorption capacity of the nanoparticles was tested with methylene blue dye (MB). Ten milligrams of the nanoparticles were dispersed in $100 \mathrm{~mL}$ of $50-400 \mathrm{mg} \mathrm{L}^{-1} \mathrm{MB}$ aqueous solution. The mixture was stirred magnetically to ensure that the particles were fully suspended and that the surfaces of nanoparticles were saturated with the dye. A $10 \mathrm{~mL}$ sample was withdrawn every $30 \mathrm{~min}$ and filtered. The UV-vis absorbances of these MB solutions at $\lambda_{\max }=666 \mathrm{~nm}$ were measured every $2 \mathrm{~min}$ (ref. 35) from which the adsorption capacity could be calculated. A control mixture with no nanoparticles present was also monitored. The equilibrium adsorption amount $\left(Q_{\mathrm{e}}\right)$ of the PCPF nanoparticles for MB dye was calculated using the following equation (eqn (1)).

$$
Q_{\mathrm{e}}=v \frac{\left(C_{0}-C_{\mathrm{e}}\right)}{m}
$$

where $C_{0}$ and $C_{\mathrm{e}}\left(\mathrm{mg} \mathrm{L}^{-1}\right)$ are the initial and equilibrium concentrations of the dye solution, respectively, $\nu$ is the volume of the dye solution and $m$ is the weight of nanoparticles.

\section{Results and discussion}

In aqueous solution, Tween-80 disperses in the form of spherical, core-shell micellar structures in which the core is made up from hydrophobic $\mathrm{C}-\mathrm{C}$ chains and the shell consists of polar $-\mathrm{OH}$ groups. ${ }^{38}$ The formation of the alumina nanoparticles proceeds inside the cores of the small micelles of Tween-80 in two steps. The first step is nucleation and the second is the growth of the nanoparticles. Formamide $\left(\mathrm{HCONH}_{2}\right)$ plays an important role in the formation of the nanoparticles as it decomposes into $\mathrm{NH}_{4}{ }^{+}$and $\mathrm{OH}^{-}$ions in water. The $\mathrm{OH}^{-}$ions react with $\mathrm{Al}^{3+}$ ions to form $\mathrm{Al}(\mathrm{OH})_{3}$ and precipitation occurs once the $\mathrm{pH}$ value of the solution reaches the level necessary for precipitation. This process is referred to as homogeneous precipitation..$^{39,40}$ Subsequently, calcination of the $\mathrm{Al}(\mathrm{OH})_{3}$ in an inert atmosphere leads to the formation of the alumina nanoparticles (Fig. 1).

The functional groups of nanoparticles were examined by FT-IR spectroscopy [Fig. 2(A)]. The prominent peak at $3410 \mathrm{~cm}^{-1}$ is associated with the $\mathrm{OH}$ stretching vibrations of the $\mathrm{Al}-\mathrm{OH}$ moieties. Moreover, Tween-80 introduces three additional - $\mathrm{OH}$ groups onto the surface of the synthesized nanoparticles and these groups may play an important role in the surface stabilization of these nanostructures. The peaks in the 400-1000 $\mathrm{cm}^{-1}$ range confirmed the formation of the $\gamma$-phase of 


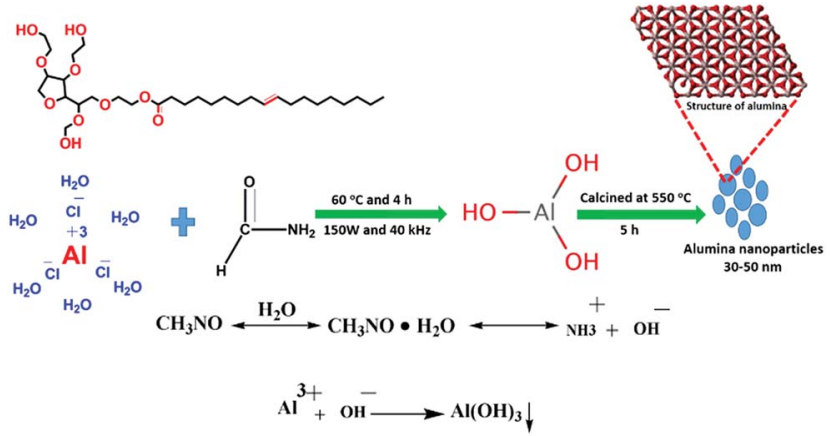

Fig. 1 Synthesis scheme for the formation of alumina nanoparticles.

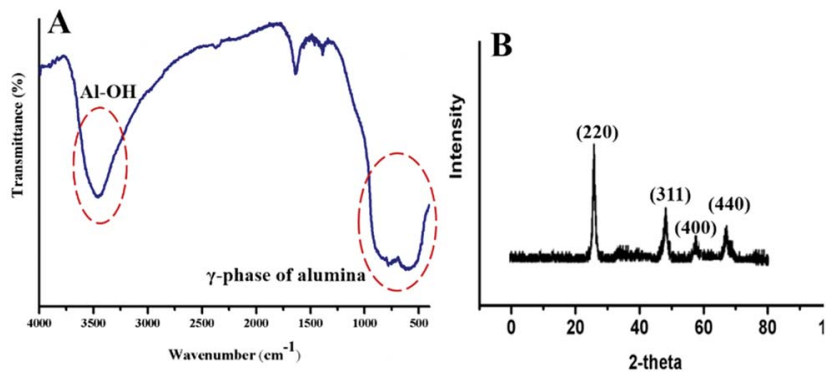

Fig. 2 FT-IR (A) and XRD (B) analyses of the nanoparticles.

alumina. The peaks at 880,795 and $630 \mathrm{~cm}^{-1}$ are attributed to the asymmetric stretching, symmetric stretching and bending vibrations of the Al-O-Al bonds, respectively. ${ }^{41}$ The peak at $680 \mathrm{~cm}^{-1}$ confirmed the octahedral arrangement of $\mathrm{Al}^{3+} .{ }^{39}$ The other peaks in the region may be due to an impurity from Tween-80 and formamide. Fig. 2(B) shows the XRD pattern of the nanoparticles, which establishes their amorphous nature. There are four reflections at $2 \theta=25.5,47.3,57.1$ and 67.4 with their corresponding reflection planes of $220,311,400$ and 440 , respectively, ${ }^{42}$ which indicate the formation of the nanoparticles. The thermal behavior of the nanoparticles was examined by TG analysis throughout the $30-800{ }^{\circ} \mathrm{C}$ temperature range under a flow of nitrogen (Fig. 3). There is $4-6 \%$ weight loss at around $410{ }^{\circ} \mathrm{C}$, which is the thermal degradation temperature $\left(T_{\mathrm{d}}\right)$ indicating the existence of strong interactions within the alumina structure. The total weight loss is only $23 \%$ when the temperature reaches $800{ }^{\circ} \mathrm{C}$ establishing the superior thermal stability of the nanoparticles, a crucial property for any future industrial applications, such as high-temperature catalysis and the production of biomaterials.

The morphology of the nanoparticles was examined by SEM and TEM analyses (Fig. 4 and 5). Without the addition of Tween80 and formamide, aggregation of the particles occurred. Clearly, Tween-80 and formamide play important roles in controlling the size and uniform shape of the particles. The particle size distribution was also investigated through SEM analysis and most of the particles are in the $30-50 \mathrm{~nm}$ range. The size distribution also confirmed that most of the nanoparticles are almost uniform in size and have definite proportions. In addition, EDX mapping of the elements (Fig. 6) shows

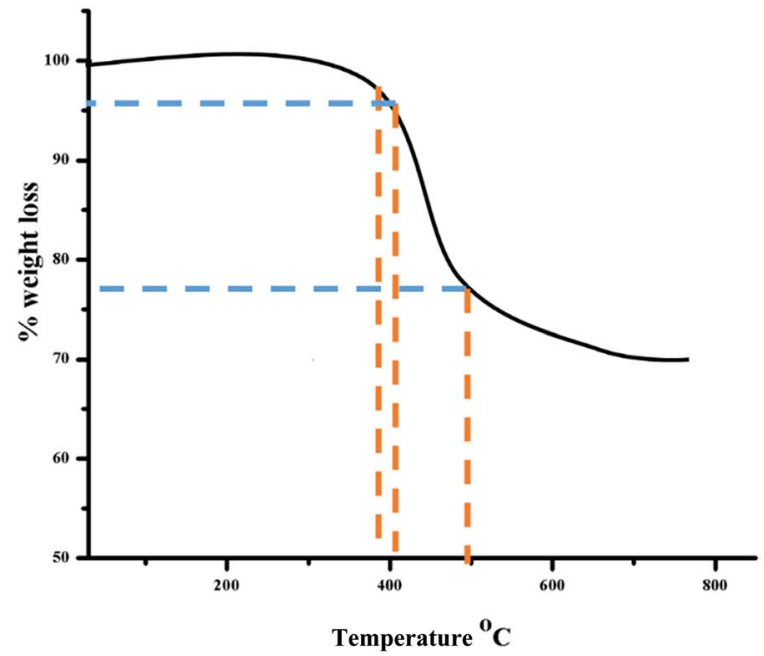

Fig. 3 TGA curve of the nanoparticles.

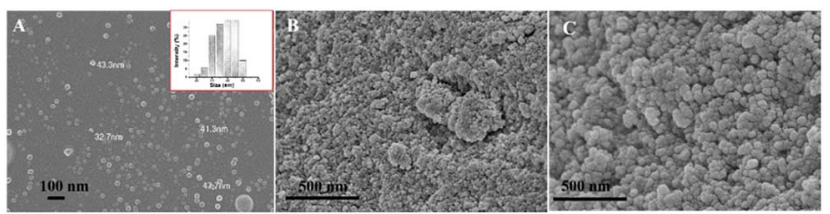

Fig. 4 SEM images of the nanoparticles: $(A)$ in the presence of Tween80 and formamide, (B) in the absence of Tween-80 and (C) in the absence of formamide. The inset in (A) illustrates the size distribution of the nanoparticles.

that the nanoparticles are mainly composed of $\mathrm{Al}$ and $\mathrm{O}$ atoms, while the existence of the $\mathrm{C}$ peaks may be due to a small amount of impurity.

Fig. 7 shows the $\mathrm{N}_{2}$ adsorption-desorption curve of the nanoparticles. Before testing, the particles were degassed at $100{ }^{\circ} \mathrm{C}$ under vacuum for $12 \mathrm{~h}$. The BET specific surface area of the nanoparticles is $16.00 \mathrm{~m}^{2} \mathrm{~g}^{-1}$ and the maximum pore size is about $4.13 \mathrm{~nm}$, as shown in Fig. 7 (inset). This specific surface area results from the porous structure of the nanoparticles. Such a structure is favorable for adsorption applications.

Many industrial companies are continuing to release various dyes and other organic compounds into the environment in their wastewater and these materials can have adverse effects on human health, plants and animals. Among these dyes, methylene blue (MB) is a stable organic compound with a heterocyclic

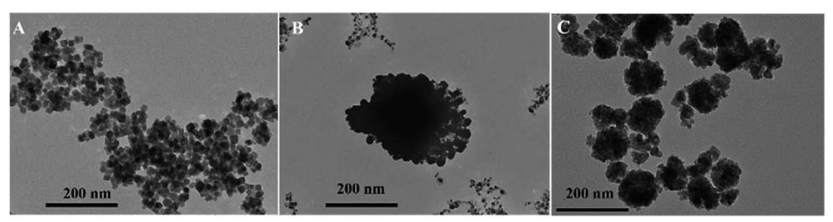

Fig. 5 TEM images of the nanoparticles $(A)$ in the presence of Tween80 and formamide, (B) in the absence of Tween-80 and (C) in the absence of formamide. 

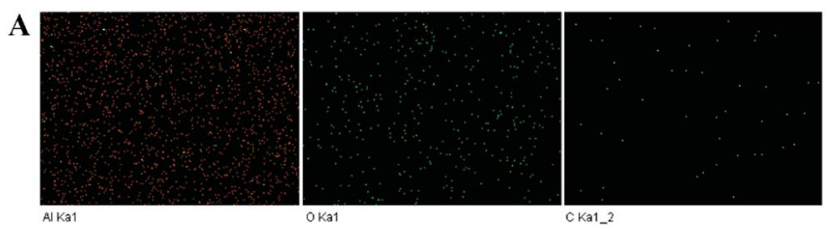

B
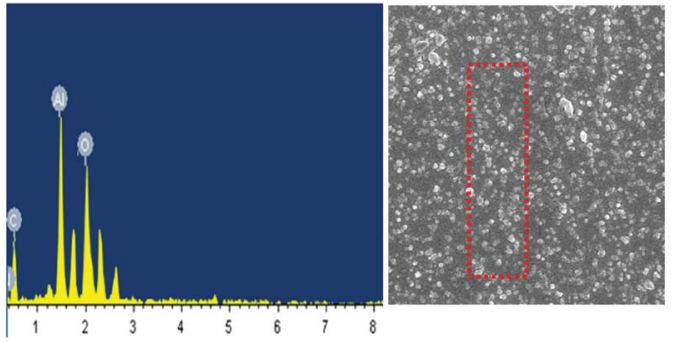

Fig. 6 EDX elemental mapping (A) and EDX (B) spectra of the nanoparticles.

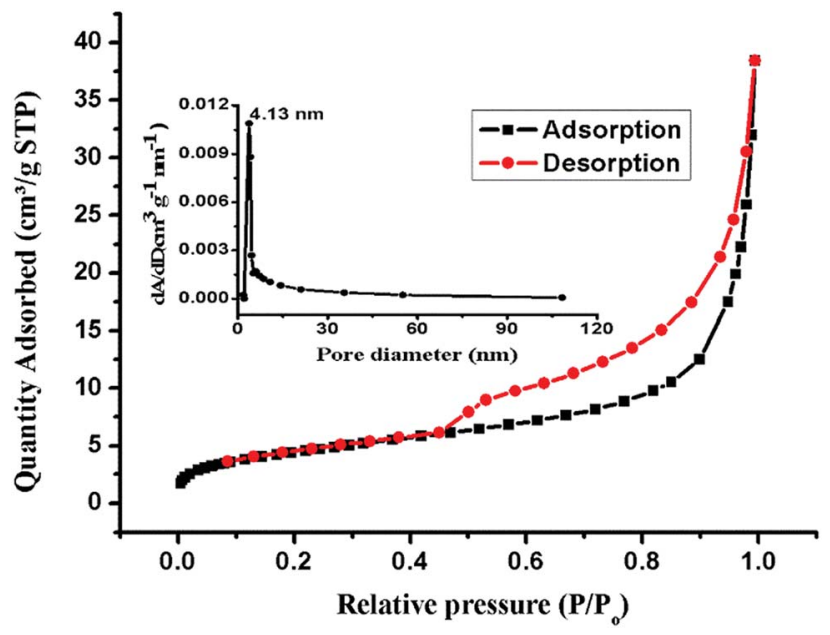

Fig. 7 Nitrogen adsorption-desorption isotherms and pore size distribution of the nanoparticles.

aromatic structure. This compound shows great resistance to heat and light, so that its degradation requires severe conditions. ${ }^{43-45}$ We used MB as a model compound to examine the adsorption properties of the $\gamma$-alumina nanoparticles. Methylene blue exhibits two characteristic visible absorption peaks at 612 and $666 \mathrm{~nm}$ and the latter peak was used to monitor the progress of the adsorption process. The $\mathrm{pH}$ has a marked effect on the adsorption properties, most probably by changing the surface charges on both the adsorbent and the adsorbate. ${ }^{39}$ The results of varying $\mathrm{pH}$ on the adsorption capacity of the nanomaterials are shown in Fig. 8. Throughout this pH range (from 2.0 to 12.0 ), the $666 \mathrm{~nm}$ peak of the dye remains unchanged. The adsorption capacity is better under basic conditions ( $\mathrm{pH} 8.0$ to 12.0 ) with the greatest adsorption (98\%) occurring at $\mathrm{pH} 9.0$ for the initial dye concentration of $50 \mathrm{mg} \mathrm{L}^{-1}$. The surfaces of metal oxides are known to be hydroxylated in aqueous solutions ${ }^{46}$ and in our case, the alumina oxide surfaces can function in an amphoteric manner and undergo acid-base reactions depending on the $\mathrm{pH}$ (see Fig. 9). Above $\mathrm{pH}$ 7.0, the net surface

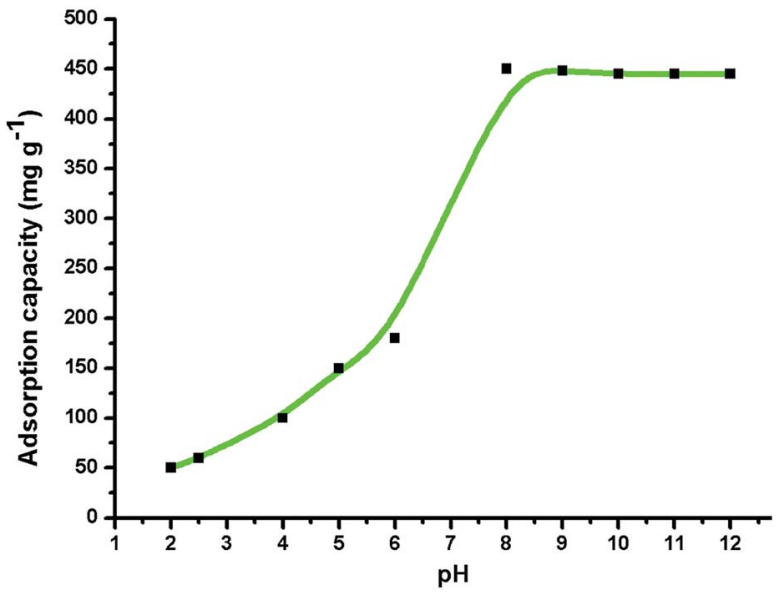

Fig. 8 Effect of $\mathrm{pH}(2.0-12.0)$ on the adsorption of $\mathrm{MB}\left(1.0 \mathrm{~g} \mathrm{~L}^{-1}\right)$ on $\gamma$ alumina nanoparticles at $30^{\circ} \mathrm{C}$

charge of the adsorbent is negative because deprotonation of the surface $\mathrm{Al}-\mathrm{OH}$ groups affords the $\mathrm{Al}-\mathrm{O}^{-}$species. This situation leads to a strong attraction for the MB cation and a high adsorption capacity. Conversely, in acidic solution, the net surface charge is positive because of protonation of the $\mathrm{Al}-\mathrm{OH}$ groups to form $\mathrm{Al}-\mathrm{OH}_{2}{ }^{+}$, which leads to repulsion between the Al- $\mathrm{OH}_{2}{ }^{+}$species and the MB cation and a much lower adsorption capacity. Similar observations have been reported for the adsorption of other dyes. ${ }^{47-49}$

The $666 \mathrm{~nm}$ absorption peak of $\mathrm{MB}$ in the visible spectrum of an aqueous solution of MB was measured with different $\mathrm{pH}$ values at different time intervals $(2-10 \mathrm{~min})$ in the presence of $10 \mathrm{mg}$ of the nanoparticles. This peak decreased rapidly [Fig. 10(A)] owing to the removal of MB from solution by adsorption on the nanoparticles. At the initial period of $10 \mathrm{~min}$, the adsorption capacity rapidly increased while it became stable after $10 \mathrm{~min}$. The adsorption capacity reached a value of $1000 \mathrm{mg} \mathrm{g}^{-1}$ within $10 \mathrm{~min}$ while it became almost constant in the next 10 min (Fig. 10(B)), while the peak was less decreased at $\mathrm{pH} 7.0$ as compared to $\mathrm{pH} 9.0$ as illustrated in Fig. 10(C) and the adsorption capacity for it was $808 \mathrm{mg} \mathrm{g}^{-1}$ as shown in Fig. 10(D).

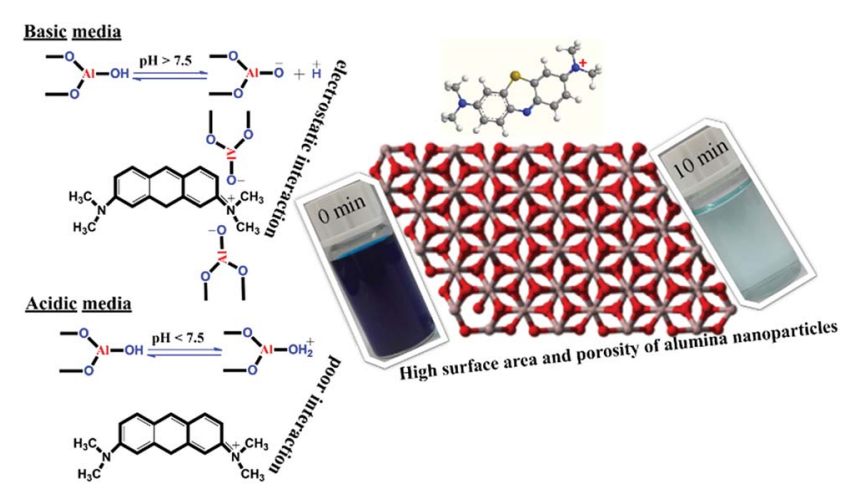

Fig. 9 Schematic of the chemistry of the adsorption of MB (100 ppm) by $\gamma$-alumina nanoparticles under different $\mathrm{pH}$ conditions. 

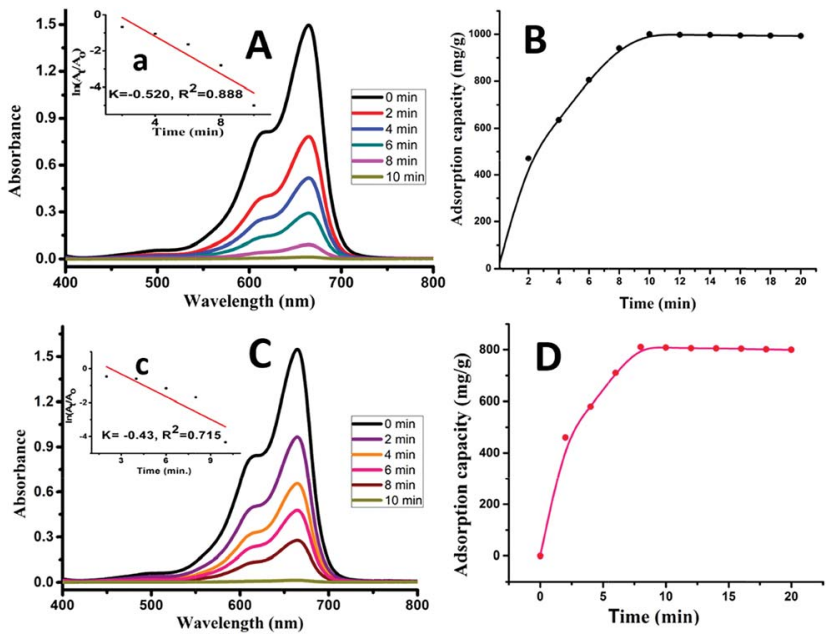

Fig. 10 Effect of contact time of $100 \mathrm{ppm}$ of $\mathrm{MB}$ on $10 \mathrm{mg}$ of the $\gamma$ alumina nanoparticles at $\mathrm{pH} 9.0(\mathrm{~A})$ and $\mathrm{pH} 7.0(\mathrm{C})$, and their adsorption capacities (B) and (D), respectively. The inset is the linear correlation between $\ln \left[A_{t} / A_{0}\right]$ and time for the degradation of $\mathrm{MB}$.

The effect of temperature $\left(30,40,50\right.$ and $\left.60{ }^{\circ} \mathrm{C}\right)$ was investigated with respect to time (5-20 $\mathrm{min}$ ) and concentration of $\mathrm{MB}$ $(50,100,150,200,300$, and $400 \mathrm{ppm})$ at a $\mathrm{pH}$ of 9.0 as illustrated in Fig. 11(A and B). Increasing the temperature increases the adsorption capacity, which went from 868 to $1000 \mathrm{mg} \mathrm{g}^{-1}$. When the initial concentration of $\mathrm{MB}$ was $50 \mathrm{ppm}$, the adsorption capacities were 422, 431, 481 and $490 \mathrm{mg} \mathrm{g}^{-1}$ and when the initial concentration reached $400 \mathrm{ppm}$, the adsorption capacities increased to 1812, 2061, 2164 and $2210 \mathrm{mg} \mathrm{g}^{-1}$ at 30, 40,50 and $60{ }^{\circ} \mathrm{C}$, respectively. Thus, the increase of adsorption capacity is fast at relatively high concentrations and temperatures within $10 \mathrm{~min}$. This high adsorption is considered to be due to strong interaction of MB with the active sites of the nanoparticles. The active sites on the $\gamma$-alumina nanoparticles have a large surface area and good porosity, two properties that favor adsorption of the planar MB molecule owing to its aromatic backbone and cationic structure under basic conditions.

The adsorption efficiencies of the recycled $\gamma$-alumina nanoparticles were also studied. The recycled nanoparticles were recovered from the original suspensions by centrifugation (4000 rpm for $30 \mathrm{~min}$ ). Adsorption by the nanoparticles proved to be only minimally affected, even after three cycles (Fig. 12).
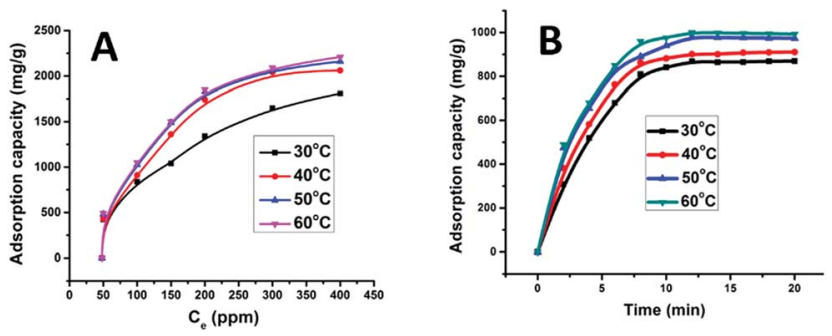

Fig. 11 Adsorption capacities at certain temperatures (30, 40, 50 and $60^{\circ} \mathrm{C}$ ): $100 \mathrm{ppm}(\mathrm{A})$, and 50,100,150, 200, 300, and $400 \mathrm{ppm}$ (B) of $\mathrm{MB}$ on $10 \mathrm{mg}$ of the $\gamma$-alumina nanoparticles within $10 \mathrm{~min}$ at $\mathrm{pH}$ 9.0.

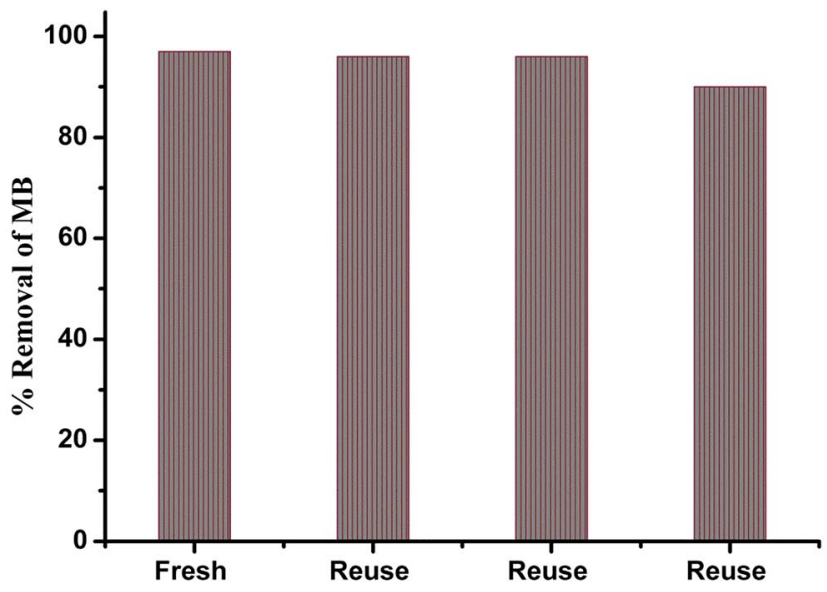

Fig. 12 Catalytic activity of MB in the presence of recycled nanoparticles under the same conditions.

\section{Conclusions}

$\gamma$-Alumina nanoparticles $(30-50 \mathrm{~nm})$ have been prepared and characterized; these nanoparticles are active for the adsorption of methylene blue (MB) dye from water. The excellent adsorption properties of these materials under basic conditions (especially at pH 9.0), even upon recycling several times, are considered to result from the electrostatic interactions between the surfaces of the nanoparticles and the cationic dye. The adsorption capacity reached a value of $1000 \mathrm{mg} \mathrm{g}^{-1}$ within $10 \mathrm{~min}$. Increasing the temperature from 30 to $60{ }^{\circ} \mathrm{C}$ significantly affected the adsorption capacity, which went from 868 to $1000 \mathrm{mg} \mathrm{g}^{-1}$. From the results of this study, it appears that $\gamma$ alumina nanoparticles will be excellent adsorbent materials for the removal of $\mathrm{MB}$, an environmentally dangerous material, from industrial wastewater in the future.

\section{Conflicts of interest}

There are no conflicts to declare.

\section{Acknowledgements}

This research work was supported by Tsinghua University, China and McGill University, Canada.

\section{References}

1 M. Madkour and F. Al Sagheer, Opt. Mater. Express, 2017, 7, 158-169.

2 R. Nivedhitha and S. Velmurugan, Int. J. Chem. Pharm. Sci., 2015, 6, 18-21.

3 M. Hao, D. Fa, L. Qian and Y. Miao, J. Nanosci. Nanotechnol., 2018, 18, 4788-4797.

4 N. R. Rane, V. V. Chandanshive, R. V. Khandare, A. R. Gholave, S. R. Yadav and S. P. Govindwar, RSC Adv., 2014, 4, 36623-36632. 
5 Y. Wu, L. Chen, X. Long, X. Zhang, B. Pan and J. Qian, J. Hazard. Mater., 2018, 347, 160-167.

6 J. Wang, Q. Zhang, X. Shao, J. Ma and G. Tian, Chemosphere, 2018, 207, 377-384.

7 J. Tian, P. Tian, G. Ning, H. Pang, Q. Song, H. Cheng and H. Fang, RSC Adv., 2015, 5, 5123-5130.

8 R. Kumar and R. Shunmugam, ACS Omega, 2017, 2, 41004107.

9 M. Schwarze, Environ. Sci.: Water Res. Technol., 2017, 3, 598624.

10 M. M. Khin, A. S. Nair, V. J. Babu, R. Murugan and S. Ramakrishna, Energy Environ. Sci., 2012, 5, 8075-8109.

11 M. M. Ibrahim, S. A. El-Molla and S. A. Ismail, J. Mol. Struct., 2018, 1158, 234-244.

12 X. Luo, H. Liang, F. Qu, A. Ding, X. Cheng, C. Y. Tang and G. Li, Chemosphere, 2018, 200, 237-247.

13 C. Regmi, D. Dhakal, T.-H. Kim, T. Yamaguchi and S. W. Lee, Nanotechnology, 2018, 29, 154001.

14 C. N. Britos, J. E. Gianolini, H. Portillo and J. A. Trelles, Biocatal. Agric. Biotechnol., 2018, 14, 221-227.

15 A. Kausar, M. Iqbal, A. Javed, K. Aftab, Z.-i.-H. Nazli, H. N. Bhatti and S. Nouren, J. Mol. Liq., 2018, 256, 395-407.

16 S. B. Khan, M. Hou, S. Shuang and Z. Zhang, Appl. Surf. Sci., 2017, 400, 184-193.

17 Y. H. Magdy and H. Altaher, J. Environ. Chem. Eng., 2018, 6, 834-841.

18 A. H. Abd El-Salam, H. A. Ewais and A. S. Basaleh, J. Mol. Liq., 2017, 248, 833-841.

19 K. M. Joshi, Asian J. Chem. Environ. Res., 2016, 9, 83-88.

20 H. Sadegh, G. A. M. Ali, V. K. Gupta, A. S. H. Makhlouf, R. Shahryari-ghoshekandi, M. N. Nadagouda, M. Sillanpaa and E. Megiel, J. Nanostruct. Chem., 2017, 7, 1-14.

21 S. G. Shinde and V. S. Shrivastava, Asian J. Chem. Environ. Res., 2016, 9, 129-132.

22 M. Arshadi, M. Mehravar, M. J. Amiri and A. R. Faraji, J. Colloid Interface Sci., 2015, 440, 189-197.

23 Q. Huang, M. Liu, J. Chen, Q. Wan, J. Tian, L. Huang, R. Jiang, Y. Wen, X. Zhang and Y. Wei, Appl. Surf. Sci., 2017, 419, 35-44.

24 Y. Jiang, Y.-N. Chang, C.-H. Deng, J. Zhang, H.-Y. Liu, J.-L. Gong, G.-M. Zeng, X.-M. Ou and S.-Y. Huang, Int. J. Biol. Macromol., 2016, 82, 702-710.

25 E. Gharibshahian, M. J. Tafershi and M. Fazli, J. Phys. Chem. Solids, 2018, 116, 241-249.

26 X. Chu, J. Wang, L. Bai, Y. Dong, W. Sun and W. Zhang, Sens. Actuators, B, 2018, 255, 2058-2065.

27 J. Liu, Q. Jin, S. Wang, P. Yu, C. Zhang, C. Luckhardt, Z. Su, R. Barua and V. G. Harris, Mater. Chem. Phys., 2018, 208, 169-176.
28 D. Sharma and R. Jha, Mater. Lett., 2017, 190, 9-12.

29 Q. Zhao, H. Zhang, X. Zhang, F. Qiu and Q. Jiang, Mater. Sci. Eng., A, 2018, 718, 305-310.

30 X. Han, F. Liao, Y. Zhang, Z. Yuan, H. Chen and C. Xu, Mater. Lett., 2018, 210, 62-65.

31 E. Vaghri, D. Dorranian and M. Ghoranneviss, Mater. Chem. Phys., 2018, 203, 235-242.

32 L.-L. Zhang, Y. Song, G.-D. Li, S.-L. Zhang, Y.-S. Shang and Y.-J. Gong, Acta Phys.-Chim. Sin., 2015, 31, 2139-2150.

33 M. Sahal, J. Magnesium Alloys, 2014, 2, 293-298.

34 J. Xiong, S. Xiong, Z. Guo, M. Yang, J. Chen and H. Fan, Ceram. Int., 2012, 38, 1815-1821.

35 S. Ali, Z. Zuhra, I. S. Butler, S. U. Dar, M. U. Hameed, D. Wu, L. Zhang and Z. Wu, Chem. Eng. J., 2017, 315, 448-458.

36 M. U. Hameed, Y. khan, S. Ali, Z. Wu, S. U. Dar, H. Song, A. Ahmad and Y. Chen, Ceram. Int., 2017, 43, 741-748.

37 K. Takei, H. Fang, S. B. Kumar, R. Kapadia, Q. Gao, M. Madsen, H. S. Kim, C.-H. Liu, Y.-L. Chueh, E. Plis, S. Krishna, H. A. Bechtel, J. Guo and A. Javey, Nano Lett., 2011, 11, 5008-5012.

38 M. Cheng, G. Zeng, D. Huang, C. Yang, C. Lai, C. Zhang and Y. Liu, Chem. Eng. J., 2017, 314, 98-113.

39 S. Banerjee, S. Dubey, R. K. Gautam, M. C. Chattopadhyaya and Y. C. Sharma, Arabian J. Chem., 2017, 10, s1629-s1638.

40 J. Wang, L. Ge, Z. Li, L. Li, Q. Guo and J. Li, Ceram. Int., 2016, 42, 8545-8551.

41 D. S. Won, I.-S. Park, M. Park, Y. Sohn, B.-G. Kim, K. S. Nahm, K.-S. Chung and P. Kim, Curr. Appl. Phys, 2014, 14, 1245-1250.

42 S. Banerjee, in Nanomaterials for Wastewater Remediation, ed. R. K. Gautam and M. C. Chattopadhyaya, ButterworthHeinemann, Boston, 2016, pp. 239-272, DOI: 10.1016/ B978-0-12-804609-8.00010-8.

43 Z. L. Meng, Y. H. Zhang, Z. L. Zhang, Q. Zhang, P. K. Chu, S. Komarneni and F. Z. Lv, J. Hazard. Mater., 2016, 318, 5460.

44 B. Pant, M. Park, S. J. Park and H. Y. Kim, Ceram. Int., 2016, 42, 15247-15252.

45 D. Wiedmer, E. Sagstuen, K. Welch, H. J. Haugen and H. Tiainen, Appl. Catal., B, 2016, 198, 9-15.

46 M. Wawrzkiewicz, P. Bartczak and T. Jesionowski, Int. J. Biol. Macromol., 2017, 99, 754-764.

47 A. Majhi, P. Monash and G. Pugazhenthi, J. Membr. Sci., 2009, 340, 181-191.

48 C. Lei, X. Zhu, B. Zhu, C. Jiang, Y. Le and J. Yu, J. Hazard. Mater., 2017, 321, 801-811.

49 Y.-M. Zheng, N. Li and W.-D. Zhang, Colloids Surf., A, 2012, 415, 195-201. 